\title{
Chemical and thermal properties of VIP latrine sludge
}

\author{
Lungi Zuma ${ }^{1 *}$, Konstantina Velkushanova' and Chris Buckley ${ }^{1}$ \\ 'Pollution Research Group, Department of Chemical Engineering, University of KwaZulu-Natal, Durban, 4000, South Africa
}

\begin{abstract}
This study investigated the chemical and thermal properties of faecal sludge from 10 dry VIP latrines in Bester's Camp in the eThekwini Municipality, Durban, South Africa. Faecal sludge samples were selected at different depths and from the front and back sections of 10 VIP latrines during a manual emptying process. The samples were analysed for: moisture content; volatile solids; chemical oxygen demand; ammonia; total Kjeldahl nitrogen; $\mathrm{pH}$; orthophosphate; thermal conductivity; calorific value and heat capacity. These properties will facilitate the design of faecal sludge emptying and treatment equipment. A manual sorting of the pit contents was carried out to determine the categories and amounts of household waste present. There was a significant difference in the moisture, volatile solids, chemical oxygen demand, ammonia, total Kjeldahl nitrogen and orthophosphate content of the faecal sludge between the front and back sections of the pit. There was minimal change in the thermal properties within the pit. The median values through the pit of each property analysed were: moisture content $-0.81 \mathrm{~g}$ water/g wet mass; volatile solids $-1.5 \mathrm{~g}$ VS/g ash; COD - $1.7 \mathrm{~g} \mathrm{COD/g}$ ash; ammonia nitrogen - $10 \mathrm{mg} \mathrm{NH}$-N/g dry mass; TKN - $39 \mathrm{mg} \mathrm{N} / \mathrm{g}$ dry mass; $\mathrm{pH}-8.03$; orthophosphate $-0.06 \mathrm{mg} \mathrm{PO}_{4} / \mathrm{g}$ dry mass; thermal conductivity $-0.55 \mathrm{~W} / \mathrm{m} \mathrm{K}$; calorific value $-14 \mathrm{~kJ} / \mathrm{g}$ dry mass; heat capacity $-2.4 \times 10^{3} \mathrm{~kJ} / \mathrm{kg} \mathrm{K}$. On average, $87 \%$ of pit content is faecal sludge; the remainder consists of wastes such as paper, plastics and textiles.
\end{abstract}

Keywords: faecal sludge, VIP latrines, chemical properties, thermal properties

\section{INTRODUCTION}

In South Africa, 31.3\% of households have their sanitation needs met by a pit latrine; $12.5 \%$ are ventilated improved pit (VIP) latrines while $18.8 \%$ are pit latrines without ventilation (Statistics SA, 2011). VIPs are on-site sanitation systems; the excreta is stored on site prior to being emptied and disposed. The material that is emptied from the pits is known as faecal sludge. In the eThekwini Municipality there are an estimated 40000 VIP latrines. Because the toilet is a permanent structure, the pits need to be emptied when they become full. The municipality empties the pits on a 5 -year cycle at no cost to the household (EWS, 2011); this faecal sludge requires treatment and/or disposal in a responsible manner. Technology development for collection, transport, treatment and disposal of faecal sludge requires detailed knowledge of the properties of the faecal sludge that is emptied. The processes occurring in a VIP are: filling (with faecal matter, water and other material); water transfer in and out of the pit; biological transformation; and pathogen deactivation (Buckley et al., 2008). These processes affect the properties of the faecal sludge within the pit.

The amount of urine and faeces excreted by an individual varies widely, even locally, depending on water consumption, diet, and occupation (Thye et al., 2011); this will affect the properties of the faecal sludge collected in the pit latrine. The properties of the faecal sludge will determine the emptying techniques (pumping, vacuum evacuation or manual emptying with spades, forks and buckets), transportation (tankers or skips), processing (anaerobic digestion, composting, drying or incineration) and final disposal (burial, incineration or agriculture) (Heinss et al., 1999; Harrison and Wilson, 2012; Radford et al., 2011). The properties can also inform the design of future sanitation facilities.

\footnotetext{
* To whom all correspondence should be addressed.

e-mail: lungiswazuma@gmail.com

Received 18 June 2014; accepted in revised form 11 June 2015
}

There are previous studies which have been conducted around the sampling and analysing of pit latrine sludge in the eThekwini Municipality for specific investigations. The first study, conducted by Bakare (2011), involved sampling 16 VIP latrines at 4 depths and analysing the faecal sludge for moisture content, total and volatile solids content, chemical oxygen demand (COD) and aerobic biodegradability to determine the amount of biodegradable material present in each sample. The study was conducted in order to investigate the filling rates of VIPs and the efficacy of pit latrine additives. The second study, by Wood (2013), analysed for a wider selection of properties for samples collected at 4 depths of 2 VIP latrines - these tests included $\mathrm{pH}$, alkalinity, moisture content, volatile solids, COD, biodegradable COD, total Kjeldahl nitrogen (TKN), ammonia, total phosphorus and orthophosphate, in order to model the degradation processes in a pit and to obtain a baseline understanding of the chemical transformations in the VIP.

This study formed part of a wider study funded by the Bill \& Melinda Gates Foundation (BMGF) to characterise the contents of VIPs. The techniques developed will be applied to VIPs in other parts of Africa in order to assess the wider variability due to differences in the environment.

A difference was noted between the front and the back section of the pit; in the front section excreta are continually added through the use of the VIP latrine while no new material is added to the back section. Therefore this study extends the sample selection by conceptually dividing the pit into 2 sections (front and back) and selecting 4 samples from each section at 4 sludge depth levels; therefore 8 samples are collected from each pit. The average properties of the whole pit can be calculated by the volume-averaged mean of the properties of the 8 samples. The objective of the sampling campaign was to investigate the properties of faecal sludge along the pit depth and the two sections of the pit. 


\section{METHODOLOGY}

\section{Location}

The VIPs were all located in the peri-urban area of Bester's Camp $(-29.723189,30.977874)$ in the eThekwini Municipality, Durban, South Africa. The records of when the pits were last emptied could not be located. It is reasonable to assume they were all emptied at the same time since the municipality sweeps through the city emptying all the pits once in every 5 years, regardless of the amount of sludge in an individual pit. The type and size of the brick dwellings were similar and were all built at the same time. The population is homogeneous in terms of their income level and diet.

\section{VIP latrine emptying}

The sampling programme entailed manually emptying 10 purposefully selected VIPs. The emptying was done by Fukamela Contractors, a contractor employed by eThekwini Municipality to empty VIP latrines.

The same conceptual approach (Buckley et al., 2008) used by Bakare (2011) and Wood (2013), which describes the fate of the organic material that enters a pit latrine, was used in this study. The approach proposes 4 layers in a pit latrine as shown in Fig. 1.

This approach was used and further developed in the sampling campaign; this was conceptually achieved by dividing the pit into 2 sub-sections: a back section (not more than 200 $\mathrm{mm}$ from the back wall of the pit) and front section (under the

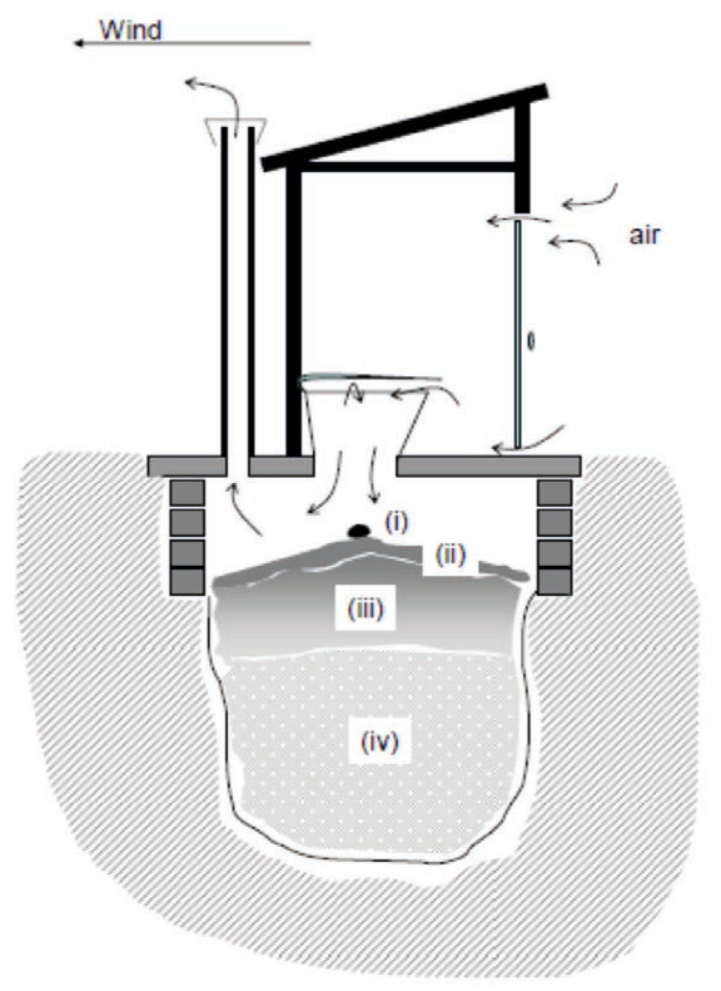

Figure 1

Diagram of a pit latrine showing the different conceptual layers (i) fresh stool; (ii) partially degraded aerobic surface layer; (iii) partially degraded anaerobic layer beneath surface; (iv) completely stabilised anaerobic layer(Buckley et al., 2008) pedestal). Samples were selected in these 2 sections based on Fig. 2; therefore a total of 8 samples were selected from each pit.

\section{Sludge sampling}

The VIP sampling was carried out manually using long-handled spades and forks to remove the sludge from the pit into bins for disposal. Once the concrete back slabs of the pit had been removed (Fig. 2), a long handled fork was used to measure the depth of the sludge in the pit. This was important as not all of the pits that were emptied contained the same depth of sludge. A measuring stick was used to measure the sludge depth. Faecal sludge samples were taken at predetermined depths for laboratory analysis. The faecal sludge samples were selected purposely to exclude any household waste found within the pit, i.e., only faecal sludge samples were taken for laboratory analysis.

Figures 2 and 3 depict the various depths that were sampled within each section of the pits. A single sample was selected from each layer and approximately $1 \ell$ was placed in a plastic bag within a plastic bucket. After filling, the neck of the bag was knotted and then the bucket lid was pressed closed. Surface layer samples (to a depth of $50 \mathrm{~mm}$ ) were taken from the front and the back of the pit. In order to reach the second layer, a sludge thickness layer of between 200 and $300 \mathrm{~mm}$ was taken out of the pit and disposed. The second layer samples were then taken from the front and the back of the pit. The middle layer samples varied in depth for the different pits because of the varying sludge heights. For each pit, the middle layer came from the halfway mark of the sludge depth. Therefore, if the sludge depth was $1000 \mathrm{~mm}$, the middle layer was taken from

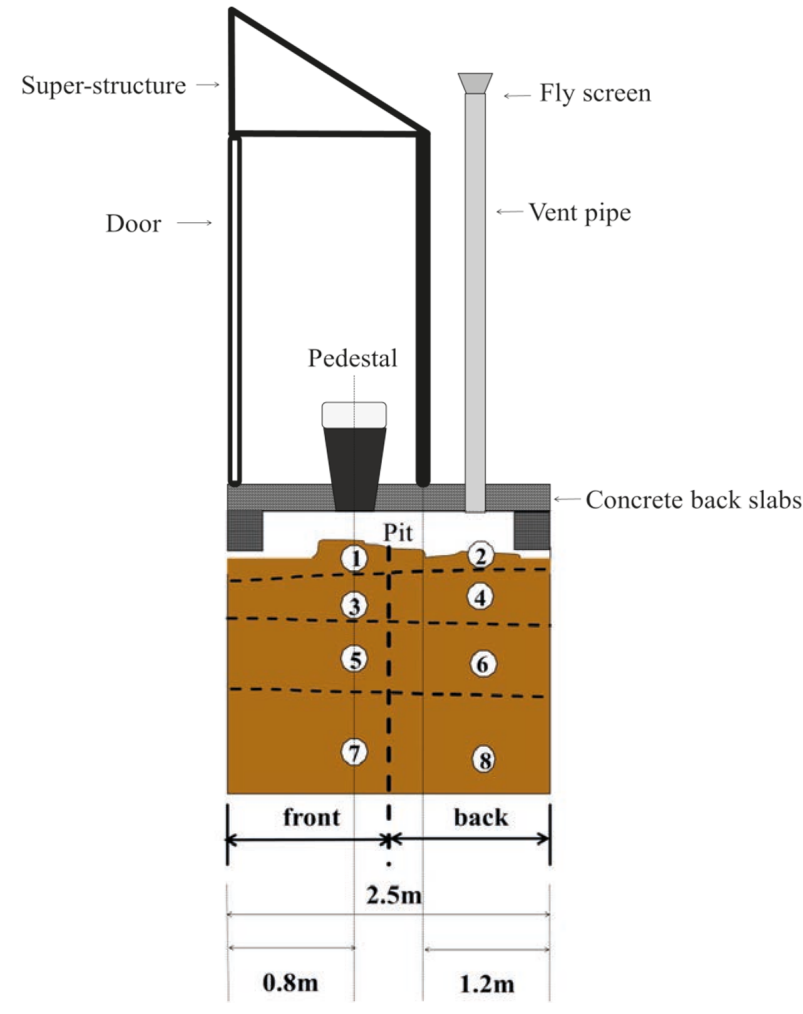

Figure 2

Diagram of a VIP latrine showing the layers from which the samples were selected in the front and back sections 
the $500 \mathrm{~mm}$ mark. The bottom layer sample was taken from the last shovel of sludge that was removed from the pit. The $1 \ell$ sludge samples were transported to the laboratory and stored at $4^{\circ} \mathrm{C}$ until analysis. Samples were analysed within 2 weeks, with the exception of the analysis of thermal properties which was conducted 6 months later on a limited number of samples. The remains of the pit contents were removed by the contractor for treatment in the latrine dehydration and pasteurisation (LaDePa) plant (Harrison and Wilson, 2012).

Figure 3 illustrates the depths of the layers of the pits that were emptied and sampled.

The faecal sludge from the different sections and layers was visually different - faecal sludge from the upper layers was a lighter brown colour as compared to the lower layers which was black and did not have an offensive odour - the stabilisation of the sludge is evident visually (Fig. 4).

\section{Laboratory analysis}

Moisture content, volatile solids, $\mathrm{COD}$, ammonia, TKN and $\mathrm{pH}$ analyses on the faecal sludge were carried out using Standard Methods for the Examination of Water and Wastewater (APHA, 2012). Where the analysis required samples in liquid

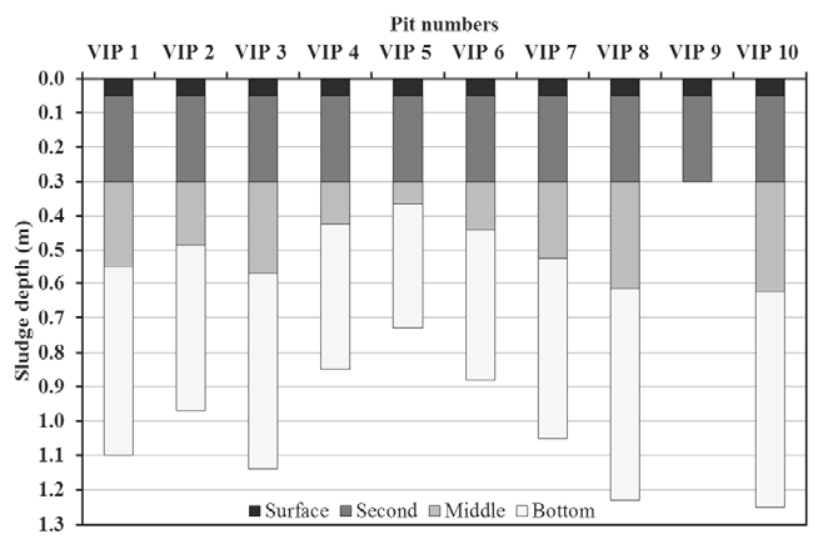

Figure 3

Sludge depths ( $m$ ) of the layers sampled in each VIP latrine. For VIP 9, due to the structure of the pit, only the surface and second layers were sampled.

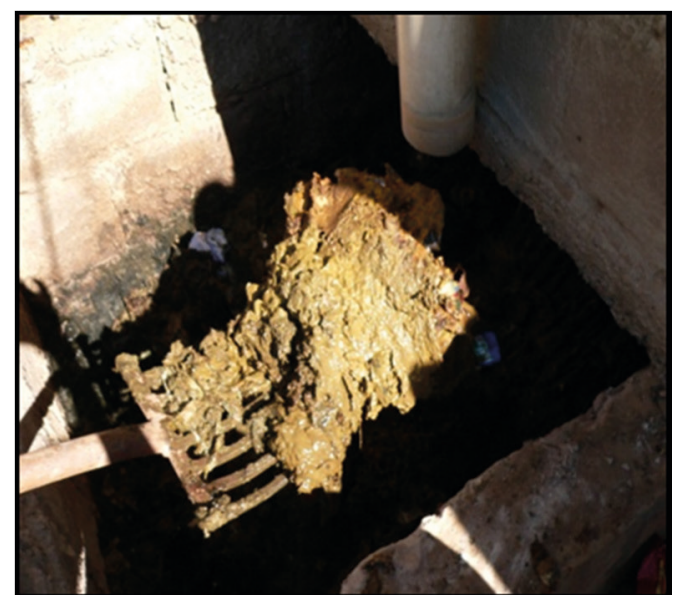

A range of faecal sludge from various points in VIP latrines: (a) second layer at the front section - VIP 5, (b) bottom layer at the back section - VIP 8 (Photo: Lungi Zuma, August 2012) form, faecal sludge dilutions were prepared by weighing a representative mass of the sample of between 1.8 and $2.0 \mathrm{~g}$ and making it up to $1 \ell$ using distilled water. The solution was mixed in a Waring blender for $30 \mathrm{~s}$ and then stored in a plastic bottle in a cold room at $4^{\circ} \mathrm{C}$ until required. Samples were removed from the cold room and allowed to come to room temperature $\left(20 \pm 5^{\circ} \mathrm{C}\right)$ before any analysis was conducted.

Orthophosphate was analysed using a Spectroquant Category No. 1.14848 kit and a Merck spectrophotometer. Thermal conductivity and heat capacity tests were conducted on the C-Therm TCi instrument and calorific value tests were conducted on the Parr 6200 Oxygen Bomb Calorimeter. Moisture content is expressed on a wet mass basis. Volatile solids, COD and calorific value are expressed on an ash basis. The remainder of the properties, except $\mathrm{pH}$, are expressed on a dry mass basis. The student $t$-tests were conducted in STATA 11.

\section{Household waste sampling}

All of the contents of VIP 1 and VIP 2 were set aside after the pits were emptied so that they could be sorted. The sorting of the pit contents gives an indication of the ratio of sludge to household rubbish in the pits, although the amount of household rubbish in pits varies from household to household.

The pit sorting was carried out manually; each bin full of faecal sludge was emptied out onto plastic sheeting and the household waste separated into the different categories (Fig. 5). The objects that were found in the pits were sorted in the following categories: sludge; textiles; feminine products; lightweight plastics; paper; stiff plastics; stone; metals; wood; hair; and glass. Thereafter the sludge and the categories of waste were weighed and expressed as fractions of the total mass.

\section{RESULTS AND DISCUSSION}

Box and whisker plots were generated using the data from the laboratory analysis for each property in each layer of the pit. A student $\mathrm{t}$-test was conducted to determine if the faecal sludge property in one part of the pit was significantly different to the same property in another section of the pit. The parts were divided by sections (front and back) and a pair-wise comparison of the different layers.

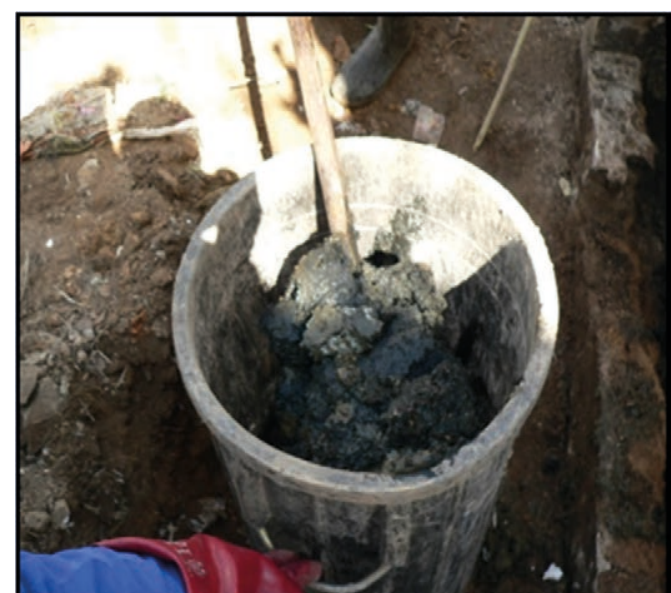




\section{Moisture content}

The trend in moisture content was as expected - decreasing mean values with increasing sludge depth (Fig. 6). The surface layer in the front section had the faecal sludge with the highest moisture content; this is expected as this is the freshest material. Overall, through the sludge depth, $90 \%$ of the samples had moisture content of between 0.69 and $0.87 \mathrm{~g}$ water/g wet mass; the median moisture content of the faecal sludge was $0.81 \mathrm{~g}$ water/g wet mass. There was a significant difference in moisture content between the:

- Front vs. back section $(p=0.0029)$

- Front second vs. front middle layer $(p=0.0469)$

- Back surface vs. back second layer $(p=0.0389)$

- Back second vs. back middle layer $(p=0.0479)$

- Back middle vs. back bottom layer $(p=0.0001)$

From its appearance during emptying, the faecal sludge with higher moisture content was less viscous than that with lower moisture content. Faecal sludge with higher moisture content could not be emptied using a fork with tines $100 \mathrm{~mm}$ apart, while faecal sludge with lower moisture content could be emptied easily with this fork.

\section{Volatile solids}

Overall, $90 \%$ of the faecal sludge had a volatile solids content of between 0.45 and $4.3 \mathrm{~g} \mathrm{VS} / \mathrm{g}$ ash and the median volatile solids content of the faecal sludge was $1.5 \mathrm{~g}$ VS/g ash (Fig. 7). In both sections of the pit there was an overall decrease of volatile solids content with increasing pit depth; this was expected because the faecal sludge becomes more stabilised at the lower depths. There was a significant difference in volatile solids content between the:

- Front vs. back section $(p=0.0001)$

- Front second vs. front middle layer $(p=0.0016)$

- Back surface vs. back second layer $(p=0.0001)$

- Back middle vs. back bottom layer $(p=0.0044)$

\section{Total COD}

Overall, $90 \%$ of the total COD of the faecal sludge was between 0.30 and $4.4 \mathrm{~g} \mathrm{COD} / \mathrm{g}$ ash with a median of $1.7 \mathrm{~g} \mathrm{COD} / \mathrm{g}$ ash

(Fig. 8). Through the whole pit, there was a decrease in COD of the faecal sludge with increasing pit depth. There was a significant difference in COD between the:

- Front vs. back section $(p=0.0001)$

- Back surface vs. second layer $(p=0.0029)$

- Back middle vs. bottom layer $(p=0.0001)$

\section{Ammonia}

$90 \%$ of the faecal sludge samples analysed had ammonia content of between 1.2 and $30 \mathrm{mg} \mathrm{NH}_{3}-\mathrm{N} / \mathrm{g}$ dry mass; the median ammonia content of the sludge was $10 \mathrm{~g} \mathrm{NH}_{3}-\mathrm{N} / \mathrm{g}$ dry mass (Fig. 9). The ammonia content in the faecal sludge decreased

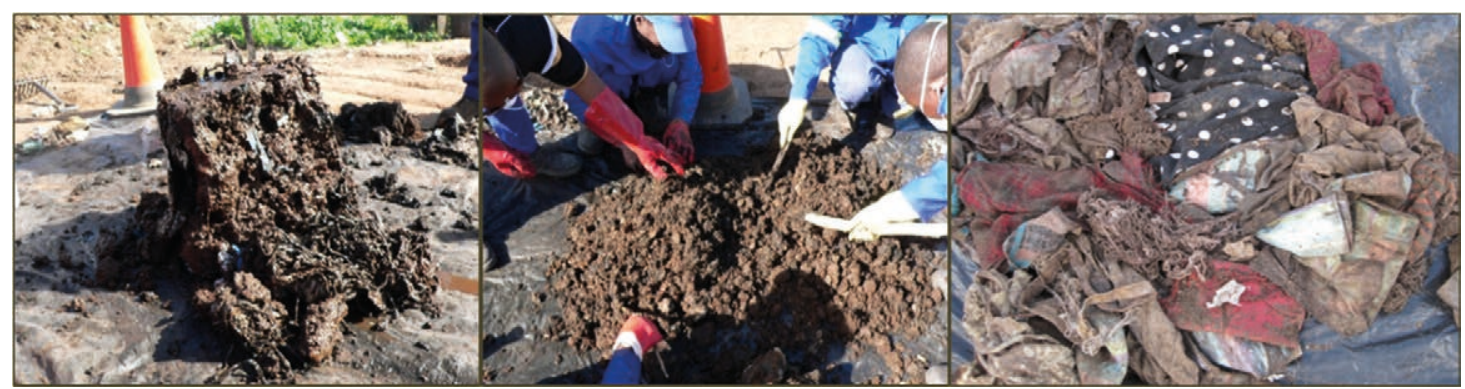

Figure 5

Manual sorting of the contents of a VIP: (a) the sludge removed from a bin, (b) sorting through the sludge, (c) textiles separated from the sludge (Photo: Lungi Zuma, September 2012)

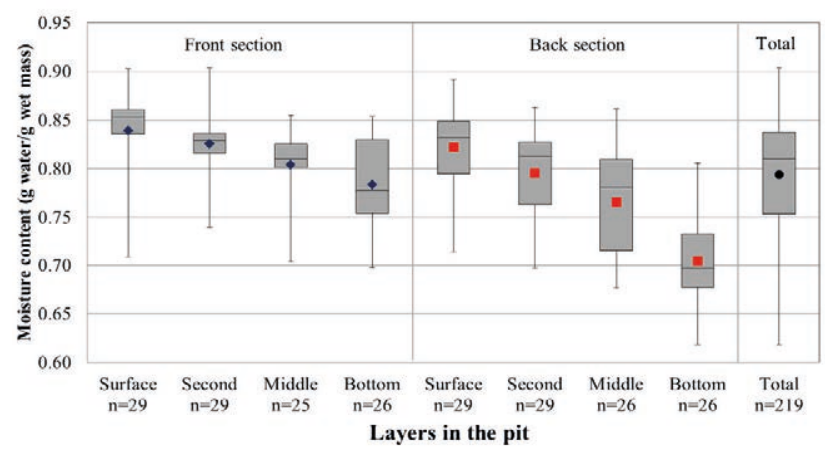

Figure 6

Box and whisker plot for the moisture content ( $g$ water/g wet mass) for the different layers of 10 dry VIPs. The extremes of the whisker represent the maximum and minimum values respectively. The outline of the box represents the 3 rd and 1 st quartile, the line in the box represents the median and the symbols represent the mean. The value in brackets below the graph represents the number of analyses.

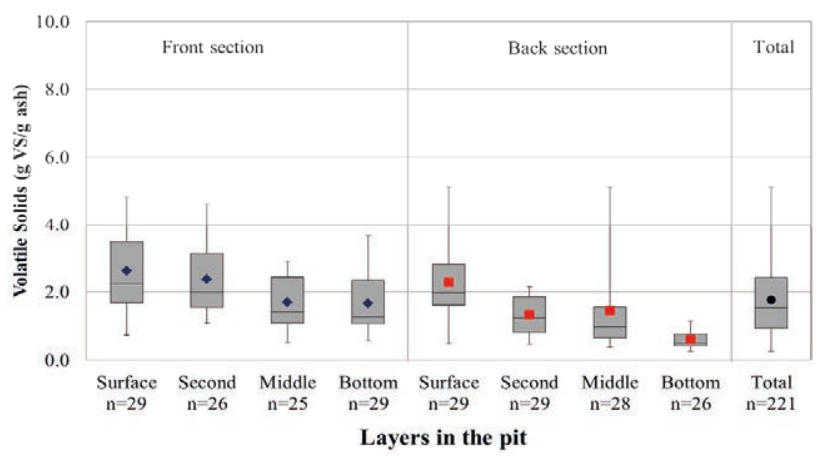

Figure 7

Box and whisker plot for the volatile solids ( $\mathrm{g}$ VS/g ash) for the different layers of 10 dry VIPS 
with increasing sludge depth for both sections of the pit. There was a significant difference in ammonia content between the:

- Front vs. back section $(p=0.0001)$

- Front surface vs. second layer $(p=0.0019)$

\section{TKN}

$90 \%$ of faecal sludge analysed had a TKN content of between 9.3 and $74 \mathrm{mg} \mathrm{N} / \mathrm{g}$ dry mass, with a median of $39 \mathrm{mg}$ N/g dry mass (Fig. 10). There was a decrease in faecal sludge TKN content with increasing pit depth in both sections of the pit. There was a significant difference in TKN between the:

- Front vs. back sections $(p=0.0001)$

- Front second vs. middle layer $(p=0.0154)$

- Back surface vs. second layer $(p=0.0032)$

\section{pH}

The $\mathrm{pH}$ range through the faecal sludge depth was between 4.7 and 8.6 (Fig. 11). The optimal $\mathrm{pH}$ for biological activity is between 6.5 and 8 , as anaerobic microorganisms, especially methanogens, exhibit a characteristic sensitivity to the extremes of $\mathrm{pH}$ (Bhagwan et al., 2008) (Anderson et al., 2003).

Faecal pH is neutral with a median value of $\mathrm{pH} 6.64$ and a range of $\mathrm{pH}$ 5.3-7.5 (Rose et al., 2015), while urine has a $\mathrm{pH}$ of 9.0-9.3 due to urea dissociation by bacterial enzymes after secretion (Jonsson and Vinneras, 2007). The aerobic and anaerobic processes that occur within the pit also contribute

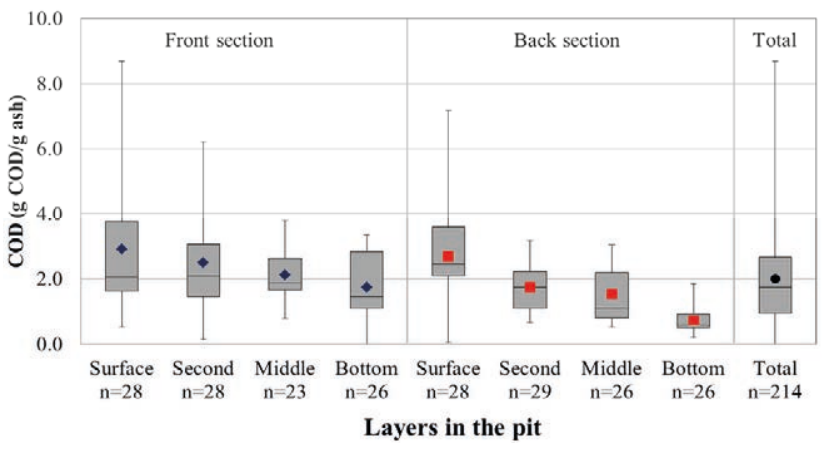

Figure 8

Box and whisker plot for the total $C O D$ ( $g$ COD/g ash) for the different layers of 10 dry VIPS

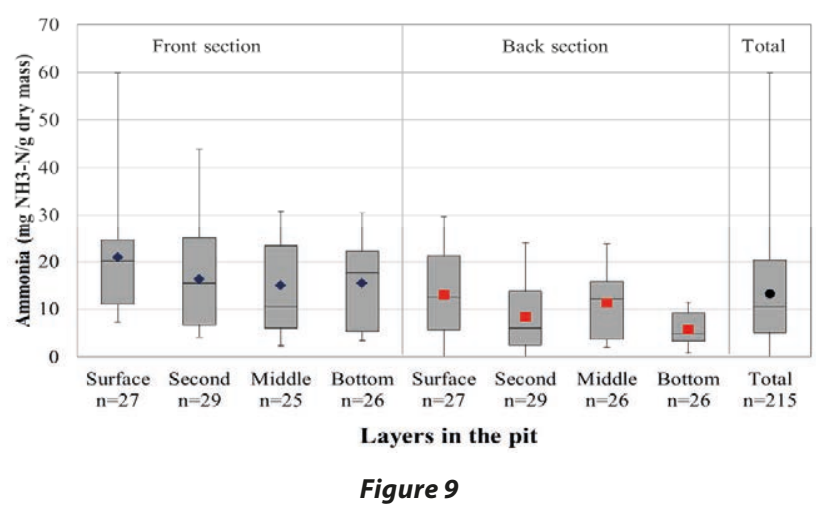

Box and whisker plot for the ammonia (mg NH3/g dry mass) content for the different layers of 10 dry VIPs to $\mathrm{pH}$ changes in the faecal sludge; therefore the $\mathrm{pH}$ of faecal sludge is a complex property which is affected by many factors.

\section{Orthophosphate}

Overall throughout the pit, $90 \%$ of the orthophosphate content of the faecal sludge was between 0.035 and $4.5 \mathrm{mg} \mathrm{PO}_{4}^{3-} / \mathrm{g}$ dry mass with a median of $0.37 \mathrm{mg} \mathrm{PO}_{4}{ }^{3-} / \mathrm{g}$ dry mass (Fig. 12). There was a significant difference in orthophosphate content between:

- Front vs. back sections $(p=0.0077)$

- Front second vs. middle layer $(p=0.0154)$

- Front middle vs. bottom $(p=0.0394)$

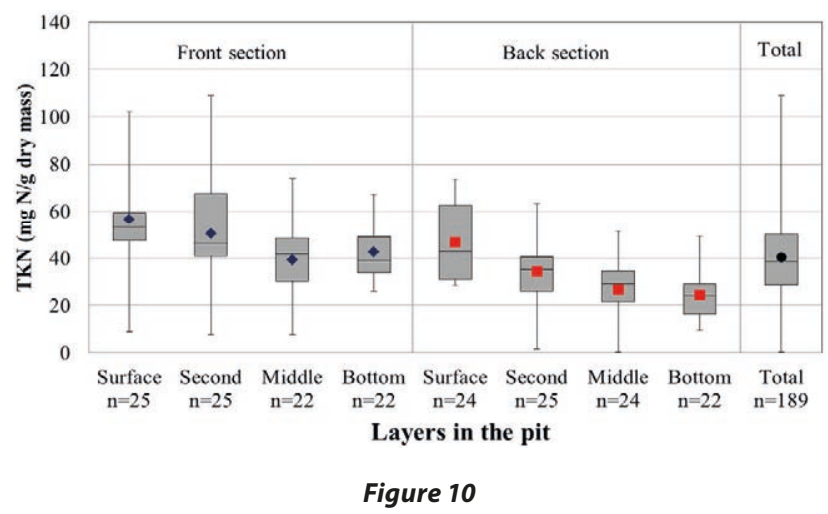

Box and whisker plot for the TKN (mg N/g dry mass) for the different layers of 10 dry VIPs

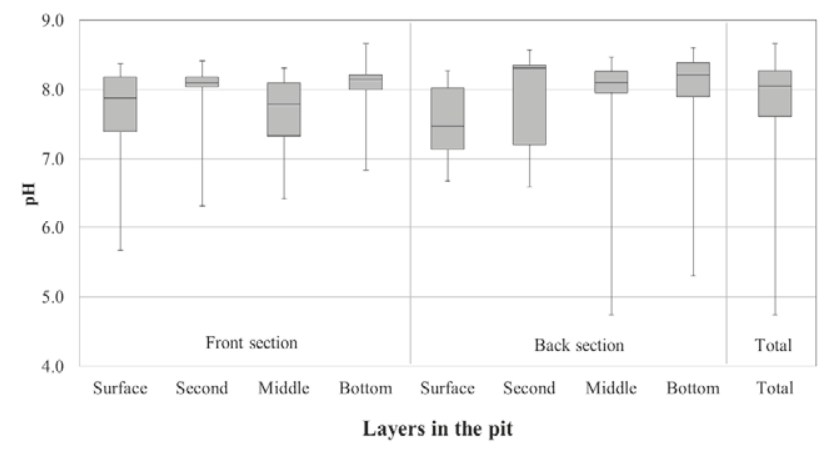

Figure 11

Box and whisker plot for the $\mathrm{pH}$ for the different layers of 10 dry VIPs

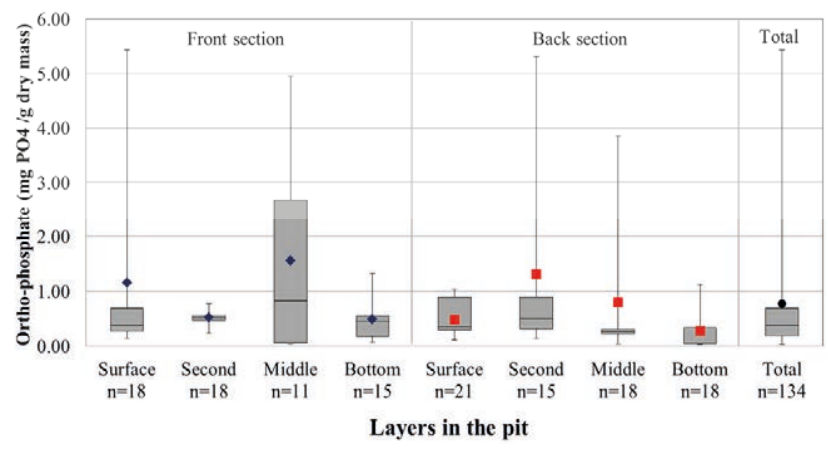

Figure 12

Box and whisker plot for the orthophosphate ( $\mathrm{mg} \mathrm{PO}_{4} / \mathrm{g}$ dry mass) content for the different layers of 10 dry VIPs 


\section{Thermal conductivity}

$90 \%$ of the thermal conductivity throughout the pit lay between 0.48 and $0.58 \mathrm{~W} / \mathrm{m} \mathrm{K}$ with a median of $0.55 \mathrm{~W} / \mathrm{m} \mathrm{K}$ (Fig. 13) this indicates a very narrow range for the thermal conductivity of faecal sludge. The thermal conductivity of water was measured to be $0.61 \mathrm{~W} / \mathrm{m} \mathrm{K}$ (Pandarum, 2013). There was no significant difference in thermal conductivity between the sections of the pit and between the pair-wise comparisons of the different layers.

\section{Calorific value}

$90 \%$ of the faecal sludge samples analysed had a calorific value of between 9.5 and $91 \mathrm{~kJ} / \mathrm{g}$ ash, with a median calorific value of $31 \mathrm{~kJ} / \mathrm{g}$ ash (Fig. 14). The calorific value of the faecal sludge decreased with increasing sludge depth in both sections of the pit; this was expected due to the decrease in organic matter in the lower layers of the pit. There was a significant difference in calorific value between the:

- Front vs. back sections $(p=0.0001)$

- Front second vs. middle layer $(p=0.0004)$

- $\quad$ Back second vs. middle layer $(p=0.0028)$

\section{Heat capacity}

Throughout the whole pit, the heat capacity of the sludge was within a narrow range; $90 \%$ of the faecal sludge samples had a heat capacity of between 1970 and $3430 \mathrm{~kJ} / \mathrm{kg} \mathrm{K}$ and the median heat capacity was $2430 \mathrm{~kJ} / \mathrm{kg} \mathrm{K}$ (Fig. 15). There was no significant difference in heat capacity between the sections of the pit and between the pair-wise comparisons of the different layers.

\section{Household waste}

The types of household waste found in VIP pits varied depending on the habits of the users, the demographics of the household and the type of cleansing material used (Table 1). The differences in the paper content of the two pits could be because of the use of toilet paper versus the use of newspaper which takes longer to degrade. These typical household wastes found in the pit need to be taken into account in the design of pit emptying devices.

TABLE 1

\begin{tabular}{|l|c|c|}
\hline \multicolumn{3}{|c|}{ The distribution of pit contents in categories } \\
\hline Category & $\begin{array}{c}\text { VIP 1 } \\
\text { \% }\end{array}$ & $\begin{array}{c}\text { VIP 2 } \\
\text { \% }\end{array}$ \\
\hline Sludge & 86.2 & 87.3 \\
\hline Paper & 8.4 & 3.8 \\
\hline Synthetic hair & 1.2 & - \\
\hline Light plastics & 0.74 & 3.4 \\
\hline Stiff plastics & 0.32 & 0.96 \\
\hline Textiles & 1.1 & 1.3 \\
\hline Feminine products & 0.42 & 2.5 \\
\hline Glass & 0.56 & - \\
\hline Metals & 0.19 & \multirow{2}{*}{$0.77^{*}$} \\
\hline Wood & 0.27 & \\
\hline Stones & 0.71 & \\
\hline
\end{tabular}

${ }^{*}$ Combined value for metals, wood and stones

\section{CONCLUSION}

The addition of material to the front section of the pit has an effect on the chemical properties of the faecal sludge as there were significant differences in chemical properties of the faecal sludge between the front and back sections. However, the thermal properties of the sludge are unaffected.

VIP latrine emptying devices have to be designed to cater for the differences between the front and back section of the pit with regards to moisture content. It is recommended that the viscosity of the faecal sludge in the layers be determined; this was seen to be visually different during the pit emptying and will influence the design of pit emptying equipment.

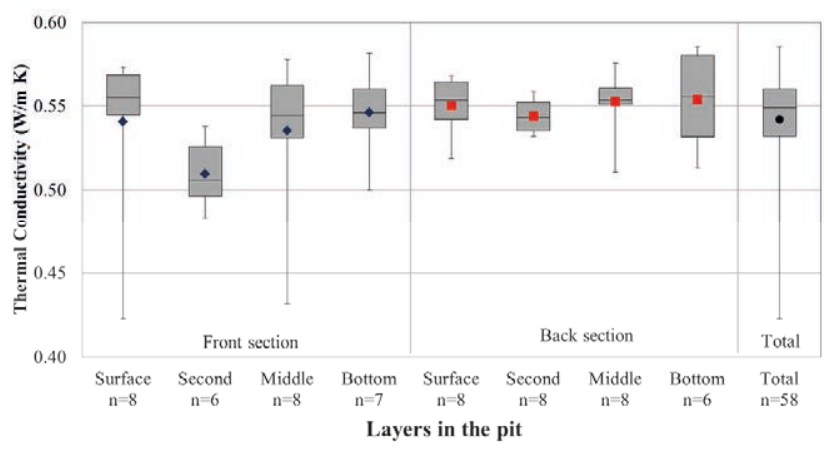

Figure 13

Box and whisker plot for the thermal conductivity $(W /(m \cdot K))$ for the different layers of 10 dry VIPs

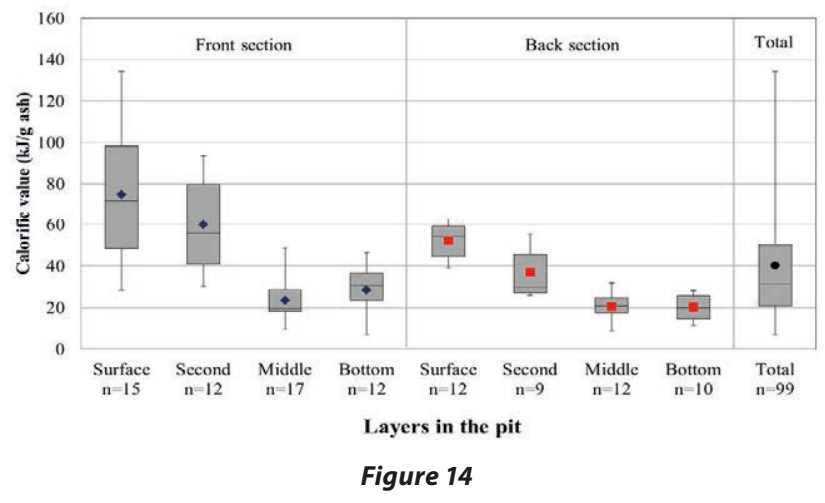

Box and whisker plot for the calorific value ( $\mathrm{JJ} / \mathrm{g}$ ash) for the different layers of 10 dry VIPs

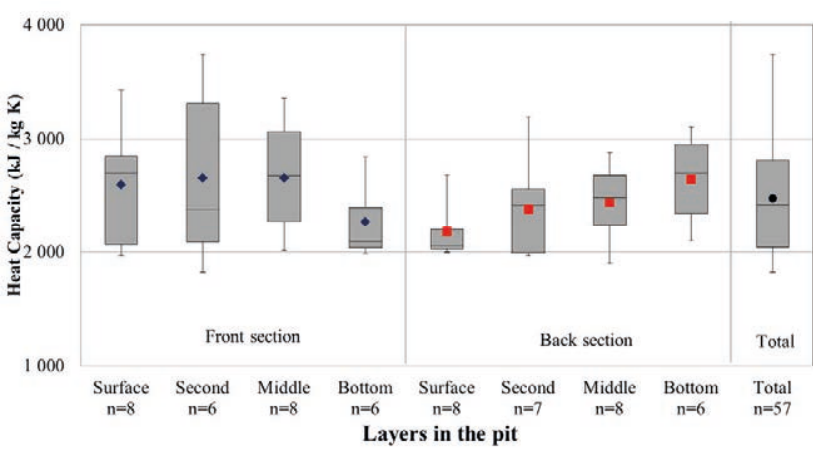

Figure 15

Box and whisker plot for the heat capacity $(\mathrm{kJ} /(\mathrm{kg} \cdot \mathrm{K}))$ for the different layers of 10 dry VIPS 
The volatile solids content and COD can both be used to determine the organic matter content of the faecal sludge. The results from these two analyses were similar, in the $90 \%$ range, for both average and median values - therefore, if only the amount of organic material is required, the volatile solids test is preferred because it is simpler and cheaper than the COD test. The faecal sludge in the back section of the pit had undergone more stabilisation than that in the front section of the pit; this conclusion is based on the average volatile solids and COD in these sections.

There was minimal transformation in the thermal conductivity and heat capacity within the pit as there were no significant differences between the different sections of the pit or between the different layers of the faecal sludge. Thus any treatment technologies that are based on faecal sludge thermal conductivity and heat capacity can be designed to cater for a narrower range than technologies based on chemical properties.

In future VIP latrine sampling to understand transformation within the pit, it is recommended that the pit be divided into front and back sections for the analysis of chemical properties. In terms of understanding the stabilisation within the pit, the bottom layer for this study was too large (there was a significant difference in the volatile solids content, COD) - it is recommended to divide the bottom layer even further, especially in the back section of the pit. Sampling of faecal sludge for thermal conductivity and heat capacity analysis does not require many layers and it is unnecessary to sample in sections; thus a composite sample of the layers and sections can be analysed for thermal conductivity and heat capacity and used as the average for the whole pit.

\section{ACKNOWLEDGEMENTS}

The authors would like to acknowledge the Bill \& Melinda Gates Foundation for the funding to complete this research.

\section{REFERENCES}

ANDERSON K, SALLIS P and UYANIK S (2003) Anaerobic treatment processes. In: Mara D and Horan N (eds.) Handbook of Water and Wastewater Microbiology. Academic Press, London.
APHA (2012) Standard Methods for the Examination of Water and Wastewater. American Public Health Association, Washington DC. BAKARE B (2011) Scientific and management support for ventilated improved pit latrines (VIP) sludge content. PhD thesis, University of KwaZulu-Natal.

BHAGWAN JN, STILL D, BUCKLEY C and FOXON K (2008) Challenges with up-scaling dry sanitation technologies. Water Sci. Technol. 58 (1) 21-27.

BUCKLEY C, FOXON K, BROUCKAERT C, RODDA N, NWANERI C, BALBONI E, COUDERC A and MAGAGNA D (2008) Scientific support for the design and operation of ventilated improved pit latrines (VIPs) and the efficacy of pit latrine additives. WRC Report No. TT/357/08. Water Research Commission, Pretoria.

EWS (ETHEKWINI WATER \& SANITATION) (2011) Water Services Development Plan for the eThekwini Municipality. EWS, Durban.

HARRISON J and WILSON D (2012) Towards sustainable pit latrine management through LaDePa. In: Proceedings of the Second International Faecal Sludge Management Conference (FSM2), 2931 October 2012, Durban.

HEINSS U, LARMIE S and STRAUSS M (1999) Characteristics of faecal sludges and their solids-liquids separation. EAWAG/SANDEC, Duebendorf.

JONSSON H and VINNERAS B (2007) Experiences and suggestions for collection systems for source separated urine and faeces. Water Sci. Technol. 56 (5) 71-76.

PANDARUM S (2013) Determination of the thermal conductivity of waste. Unpublished Chem Eng IV project report, University of KwaZulu-Natal, Durban.

RADFORD J, COFFEY M and FENNER R (2011) Developing a synthetic pit latrine sludge and a process for its fluidisation. In: Proceedings of the EWB-UK National Research \& Education Conference, 4 March 2011, London.

ROSE C, PARKER A, JEFFERSON B and CARTMELL E (2015) The characterisation of faeces and urine; a review of the literature to inform treatment technology. Crit. Rev. Environ. Sci. Technol. 45 (17) $1827-1879$.

STATISTICS SA (2011) General Household Survey Series, Volume III, Water and Sanitation, 2002-2010. Stat SA Report No. 03-18-02. Statistics SA, Pretoria.

THYE Y, TEMPLETON M and ALI M (2011) A critical review of technologies for pit latrine emptying in developing countries. Crit. Rev. Environ. Sci. Technol. 41 (20) 1793-1819.

WOOD K (2013) Transformation of faecal sludge in VIPs: Modelling fill rate with an unsteady-state mass balance. MScEng thesis, University of KwaZulu-Natal. 